\title{
Fermentation and the Ethnobiology of Microbial Entanglement
}

\author{
Andrew Flachs ${ }^{1 *}$ and Joseph D. Orkin ${ }^{2}$ \\ ${ }^{1}$ Department of Anthropology, Purdue University, West Lafayette, USA. ${ }^{2}$ Institut de Biologia Evolutiva, CSIC-Universitat \\ Pompeu Fabra, Barcelona, Spain. \\ *aflachs@purdue.edu
}

\begin{abstract}
Fermentation preserves and transforms foods through autochthonous or introduced microorganisms. Fermentation is of special interest to ethnobiologists because it relies on place- and practice-based knowledge, local flora and microbial taxa, is sensitive to cultural and ecological conditions, and illuminates the interactions through which communities shape and are shaped by the world around them. In this short topical review, we discuss recent anthropological and ethnobiological research into fermentation, arguing that this topic deserves further attention during the current moment of microbial interest across social and natural sciences. We present a typology of scholarship on human -microbial relationships that delineates three intellectual camps in this literature: neo-cultural ecology, microbiopolitics, and the environmental humanities. In light of biomedical and scientific attention to microbes-not only as threats but also as complex and beneficial actors in our lives-it is crucial to understand how socioecological practices including growing, preparing, and consuming fermented foods sustain microbial communities, heritage foodways, and human wellbeing.
\end{abstract}

Received January 2, 2019

OPENOAACCESS

Accepted June 17, 2019

Published July 18, 2019

DOI 10.14237/ebl.10.1.2019.1481

Keywords Fermentation, Ethnozymology, Microbiome, Foodways, Multispecies

Copyright (C) 2019 by the author(s) licensee Society of Ethnobiology. This is an open-access article distributed under the terms of the Creative Commons Attribution-NonCommercial 4.0 International Public License (https://creativecommons.org/licenses/by-nc/4.0), which permits non-commercial use, distribution, and reproduction in any medium, provided the original author and source are credited.

\section{Introduction}

Fermentation provides a way for ethnobiologists to imagine microbial worlds and question pro- and antibiotic entanglements with microbes, but the microbial linkages to food, knowledge, health, and heritage remain underdeveloped. Kitchens and gardens influence microbial ecology in dramatic and complex ways because humans manage agri-food systems: humans domesticate species, change habitats, and process foods in ways that have distinctive effects on microbial communities in our homes, our foods, and our guts. Ethnobiologists have a unique contribution to this growing research into human-microbial relationships. Fermentation in particular draws attention to craft food-making, taste and identity, and the practice of traditional ecological knowledge that sustains distinctive microbial ecologies. In this short topical review, we discuss three key themes in the current research around fermentation relevant to ethnobiologists: neo-cultural ecology, which understands landscapes and the human body itself as microbial ecologies shaped by cultural practices; microbiopolitics, which focuses on the political ramifications of living with microbes as allies and threats; and multispecies environmental humanities, which views human relationships through and with microbes.

Neo-Cultural Ecology, Microbiopolitcs, and the Environmental Humanities

Neo-cultural ecology approaches, in the spirit of work of Julian Steward and Robert Netting, ask about the biological mechanisms by which human-microbe interactions shape and are shaped by diet and environment in an iterative feedback loop. Neocultural ecology scholarship indicates how malleable both the human microbiome can be as well as the microbial ecologies that humans influence, citing significant microbiome differences between smallscale rural and industrialized urban human populations (e.g., Tyakht et al. 2013; Yatsunenko et al. 2012). With increasing attention to biomedical questions of probiotics and health, much fermentation scholarship is dominated by questions 
of healthy and unhealthy microbial encounters. Medical literature shows it is possible for diet in general and fermented food products in particular to influence microbial ecologies in the human gut (e.g., David et al. 2014), a point seized by corporate actors branding their foods as healthy (Derrien and van Hylckama Vlieg 2015). Moving from the scale of the human body to the scale of anthropogenic landscapes, similar research asks how microbes might define particular tastes, landraces, and microclimates. This has implications for food scholars trying to pin down how and why local tastes and knowledge shape distinct foodways. In neo-cultural ecology scholarship, terroir, the place-specific quality of food, is reimagined as a distinct microbial landscape that results from aggregated culinary and agricultural management decisions (Belda et al. 2017; Nabhan 2010; Paxson 2013).

Classic cultural ecology scholarship faced criticism from political ecologists who argued that this scholarship (1) gave too much credit to environmental conditions as the key determinant of cultural practices and (2) underplayed the historical and political conditions that shape human-environmental interactions. To counter this, neo-cultural ecology approaches to human-microbe relationships ask how humans might ideally live in partnership with microbes (Lorimer 2016), and recognize how structural forces like state regulation, antibiotic overuse, or artisanal markets might influence which humans partner with which microbes (Paxson 2013). Certainly, the combination of cultural and environmental forces works quickly on the microbial scale. For example, human microbial ecologies change rapidly in response to diet and local environmental exposure, as shown by immigrants to the US whose gut microbiomes come to resemble lifetime residents (Vangay et al. 2018). Fermentation, with its complex impacts on microbial ecologies inside and outside human bodies, illuminates how biological and sociopolitical mechanisms become entangled when they shape and are shaped by larger environments.

Microbiopolitics, particularly as developed by Heather Paxson (2013), focuses on the political ramifications of microbial encounters. This literature calls attention to how people and states seek to live with microbes: either as threats that must be destroyed because they disrupt healthy relationships, or as potential allies in the human quest for wellbeing. Microbiopolitics, following Michel Foucault's biopolitics, describes the sorts of microbial risks that communities and regulatory apparati allow through food safety regulations, moral judgements over hygiene, and governance in everyday actions. Microbiopolitics approaches take Louis Pasteur's 19th century food and safety protocols as a major point of departure in the regulation of microbial life, because Pasteur warned that microbes in the wild were potentially harmful and disruptive of otherwise healthy and productive social relationships. Where Pasteurian logic argues that microbes legitimate and even necessitate state and citizen interventions in hygiene, post-Pasteurians, as Paxson terms the rawmilk enthusiasts and artisanal cheesemakers with whom she works, discriminate between microbial encounters. Some good, or commensal, microbial interactions can be normal, healthy, and potentially lucrative while other bad, or disruptive, relationships cause harm.

These differences in the ontological politics of microbes intersect with larger questions about how humans should interact with each other. In a worldview where microbial interactions are inherently dangerous, food panics like E. coli outbreaks reveal the fragility of state hygienic regulations. Home fermenters, along with commercial producers of kombucha or raw-milk cheese beholden to food safety laws, argue that some microbial entanglement can be positive (Katz 2016; Paxson 2013) and question the extent to which regulations protect citizens and craft producers versus agribusiness corporations (Spackman 2018). In both cases, ethnobiologists can contribute to these arguments by understanding how human and microbial ecologies shape one another. Some post-Pasteurians see renewed interest in microbes as providing new models for citizenproducers to make sense of the world and reframe, or promote regulations that reframe, microbial discourse away from perilous and discrete to promising and entangled (Paxson and Helmreich 2014).

Where neo-cultural ecology asks about the biological mechanisms by which microbiomes change and microbiopolitics draws attention to regulatory and market forces governing how humans and microbes interact, scholarship from the environmental humanities investigates how human existence is made plural through entanglements with microbes. Through microbial interconnections this literature reimagines Homo sapiens as "Homo microbis" (Helmreich 2015), presenting a challenge to think of being human as 
being a good ecosystem (Benezra, DeStefano, and Gordon 2012). Humanistic literature that destabilizes the human body as a self-contained unit takes inspiration from the "holobiont", an evolutionary ecology concept wherein humans, and all complex multicellular eukaryotes, are understood to be assemblages of host organisms and their associated microbes (Bordenstein and Theis 2015). From this perspective, evolutionary forces (e.g., natural selection and genetic drift) act on the phenotypes arising from the organismal assemblage and the totality of its multispecies genomic information, or "hologenome". Viewing organisms as multispecies assemblages, the holobiont concept extends a Lamarckian evolutionary logic wherein subsequent generations inherit externally acquired microbes along with their corresponding genomes and fitness effects (Bordenstein and Theis 2015). Thus to be human is to enter into a multispecies partnership, where some microbes are welcome allies for wellbeing and some are dangerous, but where an absence of microbes is unnatural and undesirable (Lorimer 2016).

While some ethnobiologists may hesitate to engage with the political machinations of food safety regulations that dominate microbiopolitics research, environmental humanities scholarship emphasizes pungent and hyper-local cultural keystone ferments through which communities and ethnic groups stake claims to identity (Yamin-Pasternak et al. 2014). Some microbes are used to make nationalist arguments, as when Korean food scientists analyze microbial ecologies to argue that Kimchi is uniquely Korean and not Japanese (Jang et al. 2015). Others enlist microbes to make food sovereignty arguments, like the claim that Bulgarian yogurt (Yotova 2017) and Ghanaian dawa-dawa (Ham 2017) provide unique health benefits through unique Lactobacillus bacteria, a way to fight against the grain of an industrializing and homogenizing global food system. Along with signalling group identity, many ferments are live cultures and are exchanged through starters and brines. Because they carry the well-wishes and recipes of the givers with them, such exchanges are classic anthropological gifts imbued with social meaning (Jasarevic 2015; Katz 2016). Like the heirloom seeds or recipes discussed in much ethnobiological literature, gifts of ferments and starters invite recipients to join in a shared ecological practice and culturally significant taste.
Each of the three perspectives we have discussed offers ethnobiologists a way to understand microbes at the nexus of local agroecological management, food practices, and human wellbeing. Neo-cultural ecology approaches draw attention to how kitchens and gardens shape microbial ecology from human to landscape scales through culinary and agricultural practices. Microbiopolitics introduces a political ecology approach to fermented ecosystems, drawing attention to which regulatory structures protect whom, and at what cost. Finally, scholarship in the environmental humanities, interested in evolution and multispecies entanglements on the microbial scale, reimagines fermented foods as landscapes and bodies as ecosystems shared and cohabited by multiple organisms.

\section{Applying Ethnobiology to Fermentation and the Microbiome}

Ethnobiologists are centrally concerned with the ways that we shape the environment and the environment shapes us, exploring interconnections between diet, identity, and ecological relationships. In addition to scholarship documenting cultural and biological diversity through fermented food recipes, ethnobiologists have a chance to use fermentation to contribute to "Ethnobiology 5" (Wolverton 2013), in which research builds socioecological theory while strengthening local knowledge and sovereignty to help communities live with rapid shifts in ecological, political, and economic opportunities around the world. Just as the spread of industrialized agriculture and rural outmigration threaten in situ conservation of biodiversity and the cultural knowledge that sustains it, so too do these factors threaten local starters, encourage Pasteurian regulation, endanger specialized tools and knowledge that promote microbial refugia, and marginalize local food cultures (Sõukand et al. 2015). As ethnobiologists Cassandra Quave, Andrea Pieroni, and Gary Nabhan have argued most prominently, the loss of either specialized ethnozymological knowledge or local hosts for autochthonous bacteria can disrupt practice- and place -based food security for communities that use fermented foods to bolster food security, foster culturally important tastes, or anchor connections between food, identity, and health (Nabhan 2010; Quave and Pieroni 2014; Sõukand et al. 2015; Svanberg 2015). 
This brief review essay offers a typology of recent scholarship that distinguishes between research that (1) asks how cultural practices shape distinctive microbiomes within human bodies and across anthropogenic landscapes; (2) calls attention to the political and ideological dimensions of hygiene regulation; and (3) focuses on how microbes help people rethink what it means to be human or draw cultural and ethnic boundaries. Fermentation offers ethnobiologists a lens through which to draw from and contribute to these conversations. The ethnobiology of fermentation can foster theoretically rich and politically engaged research, exploring how local knowledge vested in a community shapes a dynamic ecosystem at multiple scales and creates possibilities for further cultural expression. Local variation in cultigens, food preparations, soils, and waters likely impacts microbial ecology, especially in the context of wild fermentation from autochthonous lactic acid-producing bacteria. By stressing local social and global political conditions under which these microbial relationships can exist, ethnobiologists can describe the complex feedback loops that shape microbial landscapes. Finally, an ethnobiological approach to fermentation and the microbiome can contribute to in situ conservation at various scales by celebrating taste, knowledge, health, and place as daily practices opposed to the homogenization of foods and ecologies through modernist industrialization.

\section{Declarations}

Permissions: None declared.

Sources of funding: Joseph D. Orkin is supported by the Beatriu de Pinós postdoctoral programme of the Government of Catalonia's Secretariat for Universities and Research of the Ministry of Economy and Knowledge.

Conflicts of Interest: None declared.

\section{References Cited}

Belda, I., I. Zarraonaindia, M. Perisin, A. Palacios, and A. Acedo. 2017. From Vineyard Soil to Wine Fermentation: Microbiome Approximations to Explain the "Terroir" Concept. Frontiers in Microbiology 8. DOI:10.3389/fmicb.2017.00821.

Benezra, A., J. DeStefano, and J. I. Gordon. 2012. Anthropology of Microbes. Proceedings of the National Academy of Sciences of the United States of America 109: 6378-81. DOI:10.1073/pnas.1200515109.
Bordenstein, S. R., and K. R. Theis. 2015. Host Biology in Light of the Microbiome: Ten Principles of Holobionts and Hologenomes. PLOS Biology 13:e1002226. DOI:10.1371/journal.pbio.1002226.

David, L. A., C. F. Maurice, R. N. Carmody, D. B. Gootenberg, J. E. Button, B. E. Wolfe, A. V. Ling, A. S. Devlin, Y. Varma, M. A. Fischbach, S. B. Biddinger, R. J. Dutton, and P. J. Turnbaugh. 2014. Diet Rapidly and Reproducibly Alters the Human Gut Microbiome. Nature 505:559-63. DOI:10.1038/ nature12820.

Derrien, M., and J. E. T. van Hylckama Vlieg. 2015. Fate, Activity, and Impact of Ingested Bacteria within the Human Gut Microbiota. Trends in Microbiology 23:354-66. DOI:10.1016/ j.tim.2015.03.002.

Ham, J. R. 2017. Cooking to Be Modern but Eating to Be Healthy: The Role of Dawa-Dawa in Contemporary Ghanaian Foodways. Food, Culture \& Society 20:237-56. DOI:10.1080/15528014.2017.1305827.

Helmreich, S. 2015. Sounding the Limits of Life: Essays in the Anthropology of Biology and Beyond. Princeton University Press, Princeton, NJ.

Jang, D., K. R. Chung, H. J. Yang, K. Kim, and D. Y. Kwon. 2015. Discussion on the Origin of Kimchi, Representative of Korean Unique Fermented Vegetables. Journal of Ethnic Foods 2:126-36. DOI:10.1016/j.jef.2015.08.005.

Jasarevic, L. 2015. The Thing in a Jar: Mushrooms and Ontological Speculations in Post-Yugoslavia. Cultural Anthropology 30:36-64. DOI:10.14506/ ca30.1.04.

Katz, S. E. 2016. Wild Fermentation: The Flavor, Nutrition, and Craft of Live-Culture Foods. 2nd ed. Chelsea Green Publishing, White River Junction, VT.

Lorimer, J. 2016. Gut Buddies: Multispecies Studies and the Microbiome. Environmental Humanities 8:5776. DOI:10.1215/22011919-3527722.

Nabhan, G. P. 2010. Ethnobiology for a Diverse World: Microbial Ethnobiology and the Loss of Distinctive Food Cultures. Journal of Ethnobiology 30:181-83. DOI:10.2993/0278-0771-30.2.181.

Paxson, H. 2013. The Life of Cheese. University of California Press, Berkeley, CA. 
Paxson, H., and S. Helmreich. 2014. The Perils and Promises of Microbial Abundance: Novel Natures and Model Ecosystems, from Artisanal Cheese to Alien Seas. Social Studies of Science 44:165-93. DOI:10.1177/0306312713505003.

Quave, C. L., and A. Pieroni. 2014. Fermented Foods for Food Security and Food Sovereignty in the Balkans: A Case Study of the Gorani People of Northeastern Albania. Journal of Ethnobiology 34:2843. DOI:10.2993/0278-0771-34.1.28.

Sõukand, R., A. Pieroni, M. Biró, A. Dénes, Y. Dogan, A. Hajdari, R. Kalle, B. Reade, B. Mustafa, A. Nedelcheva, C. L. Quave, and L. Luczaj. 2015. An Ethnobotanical Perspective on Traditional Fermented Plant Foods and Beverages in Eastern Europe. Journal of Ethnopharmacology 170:284-96. DOI:10.1016/j.jep.2015.05.018.

Spackman, C. C. W. 2018. Formulating Citizenship: The Microbiopolitics of the Malfunctioning Functional Beverage. BioSocieties 13:41-63. DOI:10.1057/s41292-017-0051-6.

Svanberg, I. 2015. Ræstur Fiskur: Air-Dried Fermented Fish the Faroese Way. Journal of Ethnobiology and Ethnomedicine 11:76. DOI:10.1186/ s13002-015-0064-9.

Tyakht, A. V., E. S. Kostryukova, A. S. Popenko, M. S. Belenikin, A. V. Pavlenko, A. K. Larin, I. Y. Karpova, O. V. Selezneva, T. A. Semashko, E. A. Ospanova, V. V. Babenko, I. V. Maev, S. V. Cheremushkin, Y. A. Kucheryavyy, P. L. Shcherbakov, V. B. Grinevich, O. I. Efimov, E. I.
Sas, R. A. Abdulkhakov, S. R. Abdulkhakov, E. A. Lyalyukova, M. A. Livzan, V. V. Vlassov, R. Z. Sagdeev, V. V. Tsukanov, M. F. Osipenko, I. V. Kozlova, A. V. Tkachev, V. I. Sergienko, D. G. Alexeev, and V. M. Govorun. 2013. Human Gut Microbiota Community Structures in Urban and Rural Populations in Russia. Nature Communications 4:2469. DOI:10.1038/ncomms3469.

Wolverton, S. 2013. Ethnobiology 5: Interdisciplinarity in an Era of Rapid Environmental Change. Ethnobiology Letters 4:21-25. DOI:10.14237/ ebl.4.2013.11.

Yamin-Pasternak, S., A. Kliskey, L. Alessa, I. Pasternak, and P. Schweitzer. 2014. The Rotten Renaissance in the Bering Strait: Loving, Loathing, and Washing the Smell of Foods with a (Re) Acquired Taste. Current Anthropology 55:619-46. DOI:10.1086/678305.

Yatsunenko, Y., F. E. Rey, M. J. Manary, I. Trehan, M. G. Dominguez-Bello, M. Contreras, M. Magris, G. Hidalgo, R. N. Baldassano, A. P. Anokhin, A. C. Heath, B. Warner, J. Reeder, J. Kuczynski, J. G. Caporaso, C. A. Lozupone, C. Lauber, J. C. Clemente, D. Knights, R. Knight, and J. I. Gordon. 2012. Human Gut Microbiome Viewed across Age and Geography. Nature 486:222-27. DOI:10.1038/ nature11053.

Yotova, M. 2017. The "Goodness" of Homemade Yogurt: Self-Provisioning as Sustainable Food Practices in Post-Socialist Bulgaria. Local Environment 23:1063-74. DOI:10.1080/13549839.2017.1420048. 